\title{
QUALITY ASSESSMENT OF CIPROFLOXACIN TABLETS OBTAINED FROM COMMUNITY PHARMACIES IN LAGOS, NIGERIA
}

\author{
${ }^{*}$ Joda, A. E., ${ }^{+}$Tayo, F and ${ }^{++}$Aina, B. A \\ Department of Clinical Pharmacy and Biopharmacy, Faculty of Pharmacy, University of Lagos, \\ Idiaraba Campus, Idiaraba, Lagos \\ *Corresponding author email: arinolaj@gmail.com; ajoda@unilag.edu.ng Tel: 234-802-307-3233. \\ ${ }^{+}$F. Tayo: email - prof.fola.tayo@gmail.com. ${ }^{++}$B.A. Aina: email - bolajokoaina@yahoo.com \\ (Received: $25^{\text {th }}$ November, 2017; Accepted: $11^{\text {th }}$ February, 2018)
}

\begin{abstract}
Ciprofloxacin is increasingly being used in the management of various cases of infectious diseases including gonorrhoea and acute exacerbation of chronic bronchitis. As bioavailability and bioequivalence of drug products (especially multi-sourced products) and product selection have emerged as critical issues in healthcare, it is essential that products used in patient management are of acceptable quality.

Using a sampling frame of community pharmacists in Lagos obtained from the Association of Community Pharmacists of Nigeria (ACPN) Lagos State Branch, sixteen brands of ciprofloxacin $(500 \mathrm{mg})$ tablets were purchased from selected pharmacies for the study. Physicochemical tests were carried out according to BP (2007) specifications.

The results showed that the products had acceptable physical quality thus satisfactory in appearance, size and ability to abrade or be crushed. All but one of the brands tested passed the dissolution tests. A quarter of the brands tested (25\%) did not pass the chemical assay test i.e. percentage content of active ingredient.

The study concluded that not all the products tested are of sufficiently good quality with up to four brands failing the chemical assay test. This may be due to deliberate counterfeiting, failure of current good manufacturing practices (cGMP) by manufacturers or poor handling by wholesalers/retailers. This has serious impact on healthcare delivery and public health. The study recommends effective post marketing surveillance and enforcement of cGMP. Future analytical studies on ciprofloxacin should consider dissolution testing in solutions of different $\mathrm{pH}$.
\end{abstract}

Key words: Ciprofloxacin, Quality, GMP, Drug Faking, Pharmacy and Infectious Diseases

\section{INTRODUCTION}

Oral ciprofloxacin is the recommended drug for treating gonorrhea, gonococcal urethritis and the vaginal/urethral discharge syndrome in developing countries like Nigeria (Abebe et al., 2001; WHO, 2007). In addition to being effective against Neiseria gonorrhoea, ciprofloxacin is indicated for bacterial infections like urinary tract infections (UTIs), acute uncomplicated cystitis in females, chronic bacterial prostatitis, lower respiratory tract infections, acute exacerbations of chronic bronchitis and complicated intraabdominal infections caused by sensitive organisms (Andriole, 1988; O'Donnell and Gelone, 2000; Anderson and MacGowan 2003; Talan et al., 2004; Chambers 2006; Bleidorn et al., 2010). Ciprofloxacin belongs to the fluoroquinolone class of synthetic antibacterial agents which acts by inhibiting DNA gyrase (a DNA topoisomerase II enzyme unique to prokaryotes) leading to DNA strand breakage (Elsea et al., 1992; Wentland, 1993; Campoli-
Richards et al., 1988; Laurence et al., 2003; Talan et al., 2004). The successful introduction of ciprofloxacin hydrochloride (as the innovator brand, Ciproxin by Bayer $\left.{ }^{\circledR}\right)$ into the Nigerian health care scheme revolutionized therapy of most fastidious bacterial infection such as typhoid and septicaemia though the clinical efficacy of Ciproxin was seriously compromised by its very high cost and the eventual retreat of the company from the Nigerian pharmaceutical scene (Adepoju-Bello, et al., 2007; Ngwuluka et al., 2009). Concern about lowering health care costs has resulted in a tremendous increase in the use of generic drug products. This encouraged the rapid influx of multi-source ciprofloxacin hydrochloride tablets, mostly from Asian countries, into the Nigerian market (Ilupeju et al., 2001). According to the United States Food and Drug Administration (FDA), bioavailability and bioequivalence of drug products, and drug product selection have emerged as critical issues in pharmacy and medicine during the last three 
decades. Substitution of generic drugs for brand name products is highly controversial and is often met with suspicion by health care providers and patients (Covington, 1992; Meredith, 2003). Multisource drug products must satisfy the standards of quality, efficacy and safety as applicable to the innovator product for effective substitution to be achieved (Osadebe et al., 2003).

In many developing countries, drug quality is a source of concern. Routine laboratory testing of drug samples from the supply market is needed to protect public health especially in developing countries where counterfeit and substandard drugs have become a major challenge to health care services (Giri et al., 2012). Substandard and counterfeit drugs have grave consequences for public health (Christian et al., 2012). Drugs with too little or no active ingredient can cause patient death and/or lead to the development of drug resistance. Resistance at the population level renders legitimate drugs and even entire classes of drugs less effective, even for patients who did not previously take poor-quality drugs (Bate et al., 2009; Christian et al., 2012). In 1992, ten Ham reviewed the quality of drugs from many countries and concluded that generally they are substandard rather than counterfeits. Substandard medicines are made by licensed manufacturers operating within the framework of national pharmaceutical regulatory standards and include medicines sold past their expiration date, medicines that have been compromised in shipping or storage, and medicines that have some missing active ingredients or contain the wrong ratio of active ingredients (WHO, n.d.). Substandard medicines may also arise due to human error, negligence, or resource restrictions (WHO, 2003). They may result from both inadvertent and deliberate actions by a legitimate manufacturer.

The report of a WHO/IFPMA workshop held in 1992 defines a counterfeit medicine as one which is deliberately and fraudulently mislabelled with respect to identity and/or source (WHO, 1992). Although substandard and counterfeit medicines are similar in that both have serious public health implications, counterfeits are not produced by licensed manufacturers and so cannot be controlled through effective regulation and enforcement (Christian et al., 2012). Counterfeiting of medicines has become a worldwide menace (ten Ham, 1992; Shakoor et al., 1997; Graciela, 2001). However, the problem of counterfeit and substandard drugs is not just a concern for developing countries (Christian et al., 2012; Frankish, 2003; Kelesidis et al., 2007; Siva, 2010). In addition to substandard and counterfeiting tendencies, poor drug quality is linked to chemical instability especially in tropical climates (Hogerzeil et al., 1991), poor quality control during manufacture (Arya, 1995) and noncompliance with current good manufacturing practice (cGMP) guidelines by manufacturers (Maponga and Ondari, 2003).

It has been estimated that private pharmacies today are the major providers of pharmaceutical services, particularly in developing countries (Bennett et al., 1997; Stenson et al., 1998). Although public-sector services are available even in the most resource-poor countries, they are not acceptable to many clients because they do not have appropriate health personnel or the necessary medicines at all times (Johnson et al., 1996; Dixon-Woods, 2001). Private providers, whether medically qualified or not, are more acceptable to many people because they are perceived to offer better access and confidentiality, and often have the reputation of being less stigmatizing than public sector facilities (Kaffle et al., 1998; Cunningham et al., 2002). Selfmedication, following direct over-the-counter purchases from pharmacists, druggists and vendors is also common (Haider and Thayer, 1995; Adu-Sarkodie, 1997; Hart and Kariuki, 1998; Sihavong et al., 2006).

It is imperative that the quality of generic brand medicines in the market is assured for appropriate product substitution (FDA, n.d.; FDA, 1997; FDA, 2000). In vitro dissolution profiles are used as surrogates for bioequivalence testing (biowaivers). According to FDA and WHO, BSC Class I medicines qualify for biowaivers if there is $85 \%$ dissolution of the drug at $\mathrm{pH} 1.2,4.5$ and 6.8 in 15 minutes, this proves that the bioavailability of the drug is not limited by dissolution (FDA, n.d.; FDA, 1997). WHO has also set biowaiver criteria for BCS Class II and III medicines (FDA, n.d.; WHO, 2006). Ciprofloxacin is a class III drug (Wu 
and Bennet, 2005; Kasim et al., 2004).

The main aim of this study was to determine the quality of the ciprofloxacin tablets obtained from community pharmacies in Lagos.

\section{MATERIALS AND METHODS}

\section{MATERIALS}

A sampling frame of community pharmacies listed by zones was obtained from the Lagos State Branch of the Association of Community Pharmacies of Nigeria. Pharmacies were randomly selected using the Raosoft Online Sample Calculator. Sixteen ciprofloxacin brands were purchased from the pharmacies, though for some of the brands, sufficient tablets were not obtainable even on return visits. A different brand was purchased at each site until no more variants were available. Each brand was assigned a code number. NAFDAC number, manufacturing and expiry dates of the products were recorded.

\section{Instruments and equipment}

The following instruments and equipment were used for this study: Agilent 1200 Series High Pressure Liquid Chromatography, Agilent 8453 Series UV/Visible Spectrophotometer, Clifton Sonicator, Intech Tablet Dissolution Test Apparatus DA-6D Model, Grant Disintegration Apparatus L-39, Grant Tablet Friabillator L-54, Thermonik Tablet Hardness Tester DHT 200, Mettler PE 360, Micrometer Screw Gauge and a Denver Analytical Weighing Balance (Digital). Other instruments and materials include needles and syringes, pipettes, syringe filters, volumetric flasks and sample bottles.

\section{Chemicals and reagents}

The following chemicals and reagents were used in the study: acetonitrile (Fisher Scientific UK Ltd), trichloroacetic acid and deionised water (Kindly obtained from Neimeth Nigeria PLC) and ciprofloxacin pure powder (USP).

\section{METHODS}

Sixteen (16) brands of ciprofloxacin $500 \mathrm{mg}$ tablets were used in the study. Tests carried out were categorized under physical quality test, physicochemical quality tests and chemical quality tests. Tests were carried out according to
Pharmacopoeial specifications (British Pharmacopoeia, BP, 2007, and United States Pharmacopoeia, USP, 2004). Assays were carried out in triplicate while the dissolution tests were done on six tablets as indicated in the BP. Dissolution profiles were constructed for each brand.

\section{Physical Quality Tests}

The following physical properties of the tablets were assessed using British Pharmacopoeia (BP 2007) method: Uniformity of diameter and thickness, uniformity of weight, crushing strength (tablet 'hardness') and resistance to abrasion ('tablet friability').

\section{Uniformity of weight (mass)}

Twenty (20) tablets were taken and weighed individually using a Denver Analytical Weighing Balance (Digital) and the average weight was determined. The deviation of individual tablet weights from the mean weight was determined by subtracting the mean weight from the individual weight and dividing by the mean weight. BP (2007) requirement is that for tablets that weigh more than $250 \mathrm{mg}$, not more than two of the individual weights (masses) should deviate from the average weight by more than 5 per cent and none deviates by more than twice that percentage. Weight uniformity test is required to assure that the drug content in each unit dose is distributed in a narrow range around the label strength. If the drug substance forms the greater part of the oral solid dosage form, any weight variation obviously reflects variation in the content of active ingredient.

\section{Uniformity of diameter and thickness}

The diameter and thickness of each of the ten tablets was determined using a micrometer screw gauge, making sure that the tablet does not break or get chipped. The average diameter and standard deviations was determined.

\section{Friability of the tablets}

Ten tablets were accurately weighed and placed in the drum of the Grant Tablet Friabillator L-54 apparatus. The drum was set in motion for 25 revolutions per minute for a total of 4 minutes and the tablets removed and reweighed to the nearest milligram. The BP (2007) requirement is that a 
maximum weight loss of $1 \%$ of the weight of the tablets being tested is considered to be acceptable for most conventionally compressed tablets. Friability is expressed as the loss of weight and it is calculated as a percentage of the initial weight. The formula below represents the method of calculating friability:

$$
\begin{gathered}
\% \mathrm{~F} \\
\mathrm{~A}
\end{gathered}=\underline{\mathrm{A}-\mathrm{B}} \times 100
$$

Where, $\mathrm{A}=$ weight of tablets before friability test, $\mathrm{B}=$ weight after friability test.

\section{Resistance to crushing of tablets}

One tablet was placed between the jaws of the hardness tester (Thermonik Tablet Hardness Tester DHT 200), one jaw was then moved towards the other. The measurement was carried out on 10 tablets. The results are expressed as the mean, minimum and maximum values of the forces measured, all expressed in Newton $(\mathrm{N})$.

\section{Physicochemical Assay of Quality}

Physicochemical tests carried out were disintegration time and dissolution tests. These tests are useful to determine the release properties of the tablets.

\section{Disintegration time}

Distilled water was poured into the beaker of the disintegration machine. The temperature of the Grant Disintegration Apparatus L-39 was regulated at $37^{\circ} \mathrm{C}$ with the aid of a thermostated heater attached to the apparatus. Six tablets of each brand were taken and one each was placed in the six tubes of the disintegration basket before being placed into the beaker containing the disintegration medium (distilled water) and hung on the metal holder. The apparatus and timer were switched on simultaneously and the basket oscillated in an up down manner until the drug disappeared. The time taken for each tablet to disappear was recorded and the mean value calculated.

\section{Dissolution}

The various compartments of the dissolution apparatus, (Intech Tablet Dissolution Test Apparatus DA-6D Model), were thoroughly washed and rinsed with deionized water. The dissolution medium for ciprofloxacin, according to the BP, is water hence deionized water was used. Deionized water, $900 \mathrm{ml}$, was poured into each of the six round-bottom beakers suspended in the water bath of the dissolution tester. The whole set up was maintained at a temperature of $37 \pm 0.5^{\circ} \mathrm{C}$ via the inbuilt thermostated thermometer. The agitator switch was turned on and set to a speed of 50 revolutions per minute. Dissolution medium (5 $\mathrm{ml}$ ) was taken with the aid of a syringe (zero minute) just as a tablet of each brand of ciprofloxacin was dropped into the medium and filtered with a Millipore filter $(0.45 \mu \mathrm{m})$ into a sample bottle. Deionized water $(5 \mathrm{ml})$ was replaced into the beaker so as to maintain the constant volume. The filtrate $(0.5 \mathrm{ml})$ was taken and made up to $50 \mathrm{ml}$ in a $50 \mathrm{ml}$ volumetric flask to give a 1 in 100-dilution for accurate detection and the concentrations were determined by measuring the absorbance at $276 \mathrm{~nm}$ with a UV/VIS spectrophotometer. This procedure was repeated at 5, 10, 15, 30, 45 and 60-minute intervals for each of the brands of ciprofloxacin purchased. Solution of ciprofloxacin reference standard was prepared using the dissolution medium and absorbance was measured. Water was used as a blank. All the necessary corrections for dilution were made when calculating the percent of drug released and calibration curve for the dissolution was set.

\section{Standard calibration curve:}

Pure ciprofloxacin standard (primary standard), $10 \mathrm{mg}$, was weighed out using an analytical balance and this was diluted to $100 \mathrm{ml}$ to give working concentration of $100 \mu \mathrm{g}$ stock solution. From the stock solution, appropriate volumes were taken to produce concentrations of 2.5, 5.0, 7.5 and $10 \mu \mathrm{g}$ respectively. A calibration plot was obtained when these concentrations were run through the UV/VIS spectrophotometer at $276 \mathrm{~nm}$. The regression equation was obtained and used to calculate the concentration of ciprofloxacin in the resultant solution obtained from the dissolution test

\section{Content Assay}

Assay of active ingredient was done in order to determine chemical purity of the tablets. The content of ciprofloxacin in each of the brands was determined using BP (2007) specifications. The result is presented as percentage purity. 
Preparation of Mobile Phase and chromatographic conditions

The mobile phase used was $0.1 \%$ trichloroacetic acid and acetonitrile mixed together in the ratio of 60\%: 40\%. The column used for the procedure

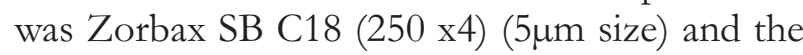
operation was carried out at a flow rate of 1.0 $\mathrm{ml} /$ minute.

\section{Preparation of standard solution for HPLC}

Five milligrams $(5 \mathrm{mg})$ of pure ciprofloxacin powder (USP) was taken and diluted with $5 \mathrm{ml}$ of deionized water to obtain a $1000 \mu \mathrm{g} / \mathrm{ml}(1 \mathrm{mg} / \mathrm{ml})$ stock solution. Standard solutions of 5, 10, 25 and $50 \mu \mathrm{g} / \mathrm{ml}$ concentrations were prepared and the standard plot for HPLC determinations was done at $276 \mathrm{~nm}$.

\section{Preparation and assay of Sample Solution}

Twenty tablets of each brand of ciprofloxacin to be used was weighed, crushed using a mortar and pestle and weight equivalent to $5 \mathrm{mg}$ of ciprofloxacin for each brand was taken and diluted to $5 \mathrm{ml}$ with deionised water to obtain a 1000 $\mu \mathrm{g} / \mathrm{ml}(1 \mathrm{mg} / \mathrm{ml})$ stock solution. The solution was sonicated for 20 minutes and filtered. A working solution for each brand containing $100 \mu \mathrm{g} / \mathrm{ml}$ of ciprofloxacin was prepared from the filtrate and the peak area of the resulting solution determined at $276 \mathrm{~nm}$ using HPLC. The solutions were made ready in the sample vials which were injected to the system at intervals. The assays were repeated three times and the results presented were the mean of the three determinations. The content of ciprofloxacin was calculated from the peak areas of the chromatograms of the test and reference standard solutions and the declared content of ciprofloxacin in ciprofloxacin hydrochloride reference standard. Each mg of $\mathrm{C}_{17} \mathrm{H}_{18} \mathrm{FN}_{3} \mathrm{O}_{3}, \mathrm{HCl}$ is equivalent to $0.9010 \mathrm{mg}$ of $\mathrm{C}_{17} \mathrm{H}_{18} \mathrm{FN}_{3} \mathrm{O}_{3}$.

\section{DATAANALYSIS}

Data obtained from the experiments carried out were compared to official specifications - BP (2007) and/or USP (2004) - and analyzed using Microsoft Excel program for calculating standard deviation and manipulating and drawing of dissolution profiles. Results are presented in tables and charts.

\section{RESULTS}

\section{Tablet Characteristics}

A record of the product samples used in the study with their manufacturing and expiry dates $(\mathrm{MD} / \mathrm{ED})$ and coating are as shown in table 1. A1 is the ciprofloxacin brand which replaced Ciproxin, the original innovator brand after the company left Nigeria. However, A2 is the market leader for ciprofloxacin products across

Table 1: Characteristics of Ciprofloxacin Brands Purchased

\begin{tabular}{lll}
\hline CODE & MD/ED & Tab. Colour \& Coating \\
\hline A1 $*$ & $05-2010 / 04-2015$ & oblong white film coated \\
A2 $\dagger$ & $02-2010 / 01-2013$ & oblong white film coated \\
A3 & $12-2008 / 11-2011$ & round orange film coated \\
A4 & $09-2009 / 08-2012$ & oblong white film coated \\
A5 & $10-2008 / 09-2011$ & oblong white film coated \\
A6 & $01-2010 / 12-2013$ & oblong white film coated \\
A7 & $07-2009 / 06-2012$ & oblong white film coated \\
A8 & $10-2009 / 11-2012$ & oblong white film coated \\
A9 & $01-2010 / 12-2013$ & oblong white film coated \\
A10 & $07-2009 / 06-2012$ & oblong white film coated \\
A11 & $07-2009 / 06-2013$ & oblong white film coated \\
A12 & $10-2009 / 09-2011$ & oblong white film coated \\
A13 & $08-2008 / 08-2011$ & oblong white film coated \\
A14 & $06-2009 / 05-2013$ & oblong white film coated \\
A15 & $10-2008 / 09-2011$ & oblong white film coated \\
A16 & $03-2009 / 02-2012$ & oblong white film coated \\
\hline KEY: $*=$ innovator product & $\dagger=$ Market leader product \\
& MD = Manufacturing Date & ED = Expiry Date
\end{tabular}




\section{Physical Quality Tests}

i. Uniformity of Weight Test

All the brands passed the uniformity of weight test as prescribed by British Pharmacopoeia, BP, (2007). In fact, only one brand (A11) had a percent deviation greater than $2 \%$ (Table 2 ).

ii. Average Diameter and Thickness

Determinations

The average diameter and thickness of the tablets with corresponding standard error of means calculated are as presented in table 2. For all the brands purchased, the average diameter and thickness varied within $5 \%$ of the mean values which is in accordance with the USP requirement (USP, 2004).

iii. Friability and Hardness Tests

Results for friability and hardness of the tablets are as shown in table 3 . All the tested brands gave friability results much less than 1\% (BP 2007 requirement). The details of the ability of the tablets to withstand crushing (hardness) are also shown

Table 2: Mean Weight, Diameter and Thickness of Ciprofloxacin Brands Purchased

\begin{tabular}{|c|c|c|c|c|}
\hline $\begin{array}{l}\text { Product } \\
\text { Code }\end{array}$ & $\begin{array}{l}\text { Mean Weight } \\
(\mathrm{mg}) \pm \mathrm{SD}(\mathrm{n}= \\
20)\end{array}$ & $\begin{array}{l}\text { Mean Percent } \\
\text { Deviation from } \\
\text { Mean Weight } \pm \text { SD } \\
(n=20)\end{array}$ & $\begin{array}{l}\text { Mean Diameter } \\
(\mathrm{mm}) \pm \mathrm{SD}(\mathrm{n}= \\
10)\end{array}$ & $\begin{array}{l}\text { Mean } \\
\text { Thickness } \\
(\mathrm{mm}) \pm \mathrm{SD}(\mathrm{N} \\
=10)\end{array}$ \\
\hline A1* & $774.2 \pm 6.0$ & $1.37 \pm 0.4$ & $18.35 \pm 0.02$ & $5.91 \pm 0.03$ \\
\hline $\mathrm{A} 2 \dagger$ & $777.2 \pm 3.8$ & $0.79 \pm 0.3$ & $16.18 \pm 0.03$ & $5.96 \pm 0.03$ \\
\hline A3 & $642.2 \pm 2.9$ & $0.77 \pm 0.3$ & $12.18 \pm 0.02$ & $5.47 \pm 0.02$ \\
\hline A4 & $686.5 \pm 2.2$ & $0.57 \pm 0.2$ & $17.20 \pm 0.04$ & $6.01 \pm 0.02$ \\
\hline A5 & $794.2 \pm 2.5$ & $0.56 \pm 0.2$ & $16.61 \pm 0.03$ & $6.01 \pm 0.03$ \\
\hline A6 & $746.9 \pm 6.7$ & $1.51 \pm 0.5$ & $19.19 \pm 0.02$ & $4.99 \pm 0.03$ \\
\hline A7 & $988.6 \pm 3.5$ & $0.64 \pm 0.2$ & $19.96 \pm 0.02$ & $5.81 \pm 0.03$ \\
\hline A8 & $762.2 \pm 6.3$ & $1.39 \pm 0.5$ & $\mathrm{nt}$ & $\mathrm{nt}$ \\
\hline A9 & $636.1 \pm 2.4$ & $0.68 \pm 0.2$ & $16.33 \pm 0.03$ & $5.04 \pm 0.03$ \\
\hline A10 & $732.1 \pm 7.3$ & $1.68 \pm 0.6$ & $19.44 \pm 0.03$ & $4.33 \pm 0.03$ \\
\hline A11 & $728.3 \pm 9.0$ & $2.49 \pm 0.4$ & $19.23 \pm 0.03$ & $4.99 \pm 0.03$ \\
\hline A12 & $759.5 \pm 2.6$ & $0.59 \pm 0.2$ & $16.66 \pm 0.03$ & $6.02 \pm 0.02$ \\
\hline A13 & $654.1 \pm 5.5$ & $1.33 \pm 0.5$ & $18.11 \pm 0.02$ & $4.85 \pm 0.03$ \\
\hline A14 & $928.2 \pm 7.1$ & $1.40 \pm 0.4$ & $19.13 \pm 0.03$ & $6.76 \pm 0.03$ \\
\hline A15 & $992.9 \pm 2.4$ & $0.44 \pm 0.1$ & $19.89 \pm 0.02$ & $5.86 \pm 0.02$ \\
\hline A16 & $754.6 \pm 6.2$ & $1.58 \pm 0.4$ & $\mathrm{nt}$ & $\mathrm{nt}$ \\
\hline
\end{tabular}

Key: $*=$ innovator product; $\dagger=$ Market leader product;nt $=$ not tested 
Table 3: Friability, Hardness and Disintegration Time (DT) of Brands Purchased

\begin{tabular}{lllll}
\hline Product code & Friability (\%) & Hardness (N) & $\begin{array}{l}\text { Disintegration } \\
\text { Time (min) }\end{array}$ & $\begin{array}{l}\text { Amount released } \\
\text { by 30 min (\%) } \pm \\
\text { SD }\end{array}$ \\
\hline A1 $*$ & 0.1 & $154.0 \pm 15.4$ & 1.25 & $95.7 \pm 15.2$ \\
A2 $\dagger$ & 0.1 & $320.8 \pm 10.2$ & 1.33 & $99.2 \pm 1.4$ \\
A3 & 0.03 & $275.7 \pm 36.6$ & 2.25 & $96.2 \pm 1.4$ \\
A4 & 0.01 & $190.3 \pm 12.5$ & 7.25 & $87.1 \pm 2.5$ \\
A5 & 0.03 & $313.9 \pm 11.0$ & 4.25 & $82.5 \pm 16.6$ \\
A6 & 0.1 & $139.3 \pm 26.9$ & 0.75 & $90.9 \pm 7.8$ \\
A7 & 0.01 & $231.5 \pm 22.5$ & 1.67 & $88.8 \pm 3.0$ \\
A8 & $\mathrm{nt}$ & $\mathrm{Nt}$ & $\mathrm{nt}$ & $51.3 \pm 5.8^{\alpha}$ \\
$\mathrm{A} 9$ & 0.1 & $193.3 \pm 27.9$ & 1.83 & $89.9 \pm 13.0$ \\
$\mathrm{~A} 10$ & 0.1 & $171.7 \pm 22.4$ & 2.75 & $97.6 \pm 9.1$ \\
$\mathrm{~A} 11$ & $\mathrm{nt}$ & $71.6 \pm 19.0$ & 0.93 & $95.1 \pm 4.9$ \\
$\mathrm{~A} 12$ & 0.1 & $281.5 \pm 22.0$ & 3.75 & $98.1 \pm 4.1$ \\
$\mathrm{~A} 13$ & 0.2 & $163.8 \pm 16.9$ & 4.92 & $91.6 \pm 3.1$ \\
$\mathrm{~A} 14$ & 0.1 & $121.6 \pm 18.1$ & 0.92 & $99.5 \pm 6.2$ \\
$\mathrm{~A} 15$ & 0.04 & $187.4 \pm 13.3$ & 1.58 & $99.2 \pm 6.6$ \\
$\mathrm{~A} 16$ & $\mathrm{nt}$ & $\mathrm{Nt}$ & $\mathrm{nt}$ & $88.0 \pm 10.2$ \\
\hline
\end{tabular}

Key: $*=$ innovator product; $\dagger=$ Market leader product; ${ }^{\alpha}$ Failed dissolution test; nt $=$ not tested

\section{Physicochemical Quality Tests}

i. Disintegration Tests

The mean disintegration times of the different brands of the ciprofloxacin tablets included in the study is shown in table 3. All the brands tested complied with the BP (2007) specified time for disintegration of film coated tablets which must be within 30 minutes. In fact, all the brands tested had a mean disintegration time of less than 8 minutes with most of them disintegrating within 2 to 3 minutes.

\section{ii. Dissolution Test}

All the brands purchased except Brand A8 passed the dissolution tests according to British Pharmacopoeia (2007) specifications which stipulates that at least $80 \%$ of the content must have been released by 30 minutes (Table 3). By 30 minutes only about $51 \%$ of product A8 had dissolved and by 60 minutes only about $73 \%$ had dissolved. Figures 1 and 2 show the dissolution profiles of the products. 


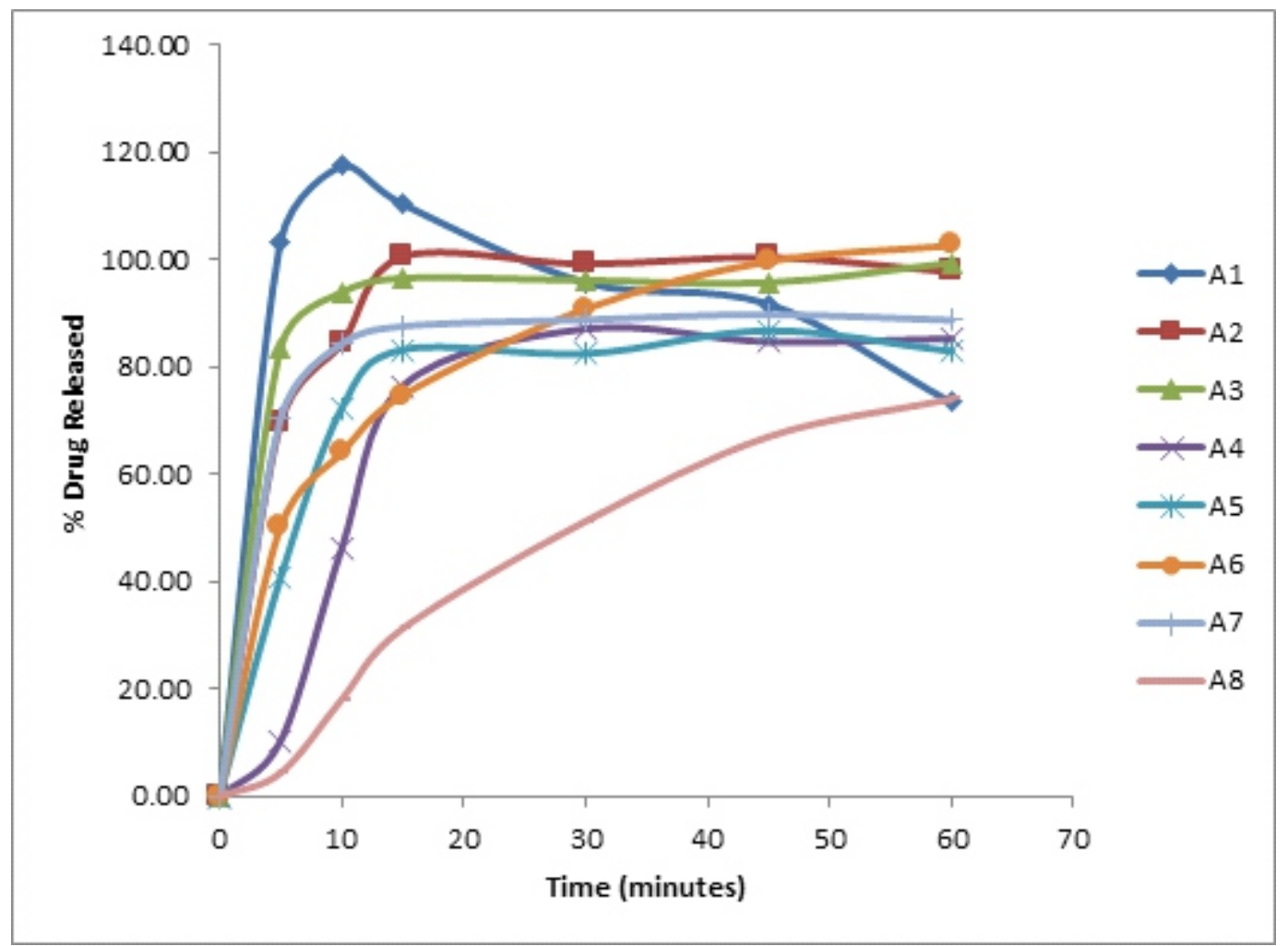

Figure 1: Dissolution profiles of the eight (8) brands (A1 - A8) of ciprofloxacin tablets in water medium.

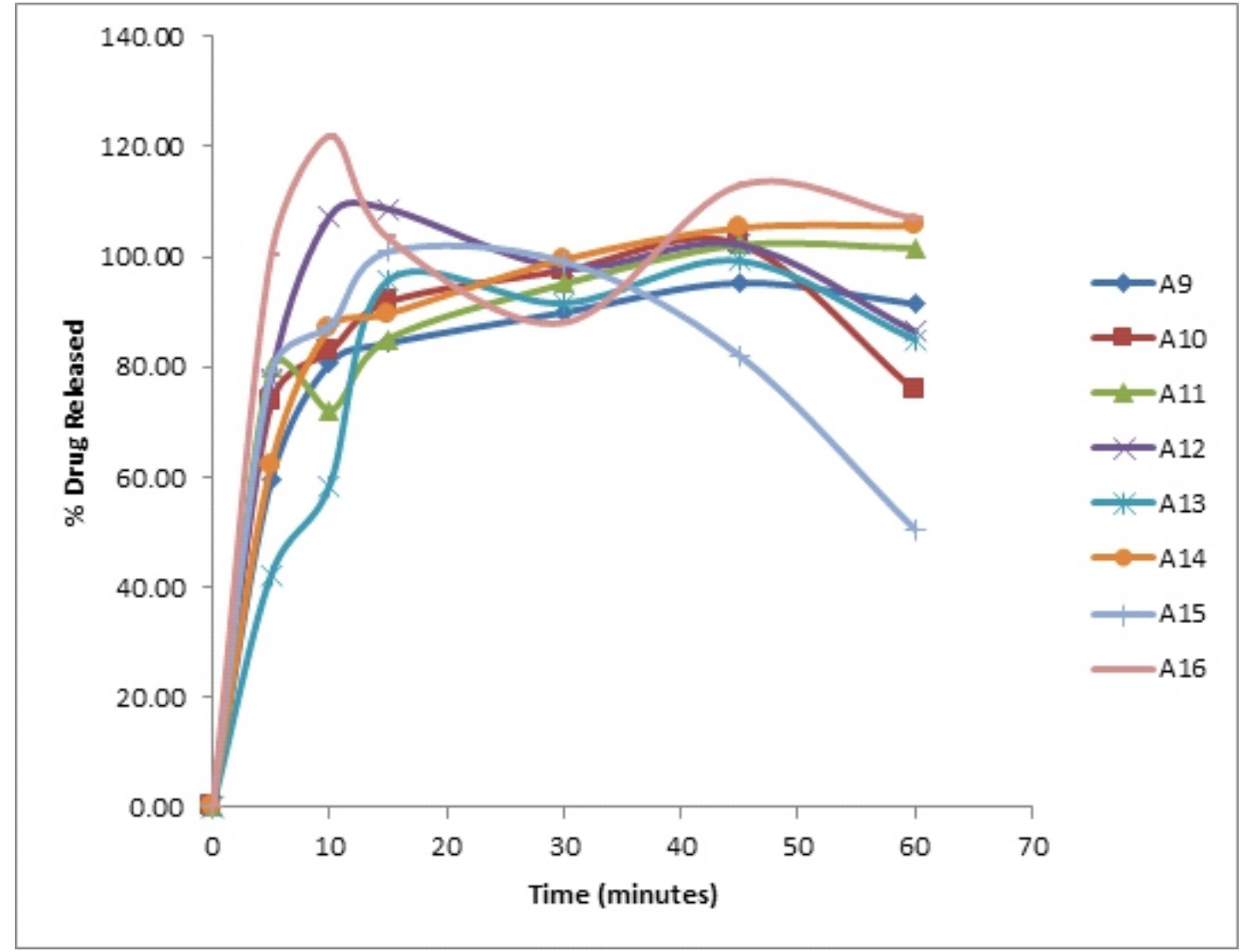

Figure 2: Dissolution profiles of the eight (8) brands (A9 - A16) of ciprofloxacin tablets in water medium 


\section{Content Assay}

The results for the mean percentage label claim for the different brands of ciprofloxacin $500 \mathrm{mg}$ tested show that $75 \%$ of the brands (12 brands) passed the BP requirement for active ingredient (ciprofloxacin) (within 95\% to 105\% of the label claim). Details are as shown in table 4.

\section{Table 4: Percentage Purity (Assay) of Brands Purchased}

\begin{tabular}{|l|l|}
\hline PRODUCT & $\begin{array}{l}\text { MEAN LABEL CLAIM } \\
\text { (\% CONTENT } \pm \text { SEM) }\end{array}$ \\
\hline A1 ${ }^{*}$ & $95 \pm 2.71$ \\
\hline A2 $†$ & $102 \pm 4.23$ \\
\hline A3 & $97 \pm 3.48$ \\
\hline A4 & $95 \pm 1.39$ \\
\hline A5 & $100 \pm 2.14$ \\
\hline A6 & $95 \pm 9.61$ \\
\hline A7 & $83 \pm 0.57$ \\
\hline A8 & $102 \pm 11.81$ \\
\hline A9 & $101 \pm 1.19$ \\
\hline A10 & $86 \pm 0.41$ \\
\hline A11 & $99 \pm 5.55$ \\
\hline A12 & $104 \pm 5.04$ \\
\hline A13 & $88 \pm 1.26$ \\
\hline A14 & $98 \pm 1.05$ \\
\hline A15 & $96 \pm 2.46$ \\
\hline A16 & $75 \pm 5.68$ \\
\hline
\end{tabular}

$*=$ innovator product $\quad \dagger=$ Market leader product

\section{DISCUSSION}

Uniformity of weight, assay, disintegration and dissolution are compendial standards to assess the quality of tablets (BP, 2007; Giri et al., 2012) while hardness and friability are referred to as noncompendial standards although friability has been included in the United States Pharmacopeia since 1995 (USP, 1995).

The results of this study showed that all the products had acceptable physical quality. This means that the tablets are satisfactory in appearance, size, friability and hardness.

Uniformity of weight of tablets serves as a pointer to good manufacturing practices (GMP) as well as amount of the active pharmaceutical ingredient (API) in this case ciprofloxacin hydrochloride contained in the formulation (BP 2007; Osonwa et al., 2011; Giri et al., 2012). Weight uniformity test is required to assure that the drug content in each unit dose is distributed in a narrow range around the label strength. If the drug substance forms the greater part of the oral solid dosage form, any weight variation obviously reflects variation in the content of active ingredient. Failure to comply with weight requirements may be considered less serious as long as the average content is within the specification (Giri et al., 2012). It is however evident that if the overall weight of the tablet varies too much so will that of the active component (Stenson et al., 1998). All the brands complied with the compendial specification for uniformity of weight (BP, 2007). The hardness or crushing strength assesses the ability of tablets to withstand handling without fracturing or chipping. It can also influence friability and disintegration as the harder a tablet, the less friable and the more time it takes to disintegrate (Ngwuluka et al., 2009; Osonwa et al., 2011; Merchant et al., 2006; Chandrasekaran et al., 2011). A force of about $4 \mathrm{~N}$ is the minimum requirement for a satisfactory tablet (Osonwa et al., 2011; Allen et al., 2004). All the tested brands had satisfactory hardness values. The compendial specification for friability is $1 \%$. All the brands tested had values below $1 \%$. Friability test is used to evaluate the tablets resistance to abrasion. 
Results from various studies on tablets usually indicate that most brands pass the physical quality tests because they are a measure of the good manufacturing practices (GMP) of the particular company involved (Adegbolagun et al., 2007; Ngwuluka et al., 2009).

Currently, dissolution tests are officially employed in predicting in-vivo bioavailability of many oral dosage forms (FDA n.d.; FDA, 1997; Emani, 2006; Ibezim et al., 2008). Disintegration could be directly related to dissolution as tablets are required to break into particles for dissolution to be possible. A drug incorporated in a tablet is released rapidly as the tablet disintegrates; a crucial step for immediate release dosage forms because the rate of disintegration affects the dissolution and subsequently the therapeutic efficacy of the medicine (Kahsay and Egziabher, 2010). The BP specifies that uncoated tablets should disintegrate within 15 minutes and film coated tablets in 30 minutes while USP specifies that both uncoated and film coated tablets should disintegrate within 30 minutes while for dissolution, the specification is that not less than $80 \%$ of the stated amount of ciprofloxacin should be released within 30 minutes. All the brands complied with the compendial specifications for disintegration while 94\% (15) brands complied with compendial specifications for dissolution. Although no bioavailability study was carried out, failure of a brand to meet the B.P. requirements for dissolution indicates formulation differences that could result in differences in bioavailability which result in differences in therapeutic effect (Adegbolagun et al., 2007).

This study revealed that a quarter of the brands purchased from the pharmacies did not comply with the chemical test i.e. percentage content of active ingredient. This figure is high and is unlike a similar study carried out in Ethiopia where all brands of ciprofloxacin tested passed the chemical test (Kahsay and G/Egziabher, 2010). Shakoor et al., (1997) assessed the quality of antimalarial and antibacterial drugs obtained from retail outlets in Nigeria and Thailand and found that $36.5 \%$ of the products were substandard. Taylor et al., (2001) analyzed the contents of drugs from pharmacies in Nigeria and found that about half of the preparations had concentrations of the drug outside upper and lower pharmacopoeia limits. Surveys carried out in other parts of Nigeria on ciprofloxacin quality gave different results. For instance, Adegbolagun et al., (2007) reported that $40 \%$ of the brands tested in Ibadan failed the chemical test while the researchers in Jos reported $17 \%$ failure rate (Ngwuluka et al., 2009). Using the WHO definition for counterfeiting (WHO, 1992), the variations found in content of active ingredient and weight varies above or below recognized limits thus pointing to substandard products probably because of problems in good manufacturing practice (GMP) or poor handling rather than to deliberate counterfeiting. Thus, regulations pertaining to product quality needs to be enforced by the regulatory agencies and strictly adhered to by drug companies, wholesalers and retailers in order to assure that products of acceptable quality are taken by the consumer.

\section{LIMITATIONS OF THE STUDY}

Unavailability of sufficient quantities of some brands despite repeated calls to the pharmacies to purchase more of the same batch as promised.

\section{CONCLUSION}

The results obtained in this study show that quality of ciprofloxacin tablets obtained in the pharmacies are not all acceptable with up to four (4) brands failing to meet pharmacopoeial specifications. This may be due to deliberate counterfeiting or to failure of good manufacturing practices by manufacturers or poor handling by wholesalers or retailers. The role of effective drug regulation as an instrument for controlling provision of drugs through community pharmacies cannot be overemphasized. Though, the required legal framework is in place, lack of monitoring and enforcement of the laws provide a loophole for unscrupulous or careless manufacturers to slip through. Post marketing surveillance, regular inspection of manufacturing outfits, wholesale outlets and pharmacies, and monitoring of pharmaceutical imports and good manufacturing practices are essential in assuring that the publics' health is not compromised by drug intake. It is recommended that post marketing surveillance be made more effective and that regular supervision and enforcement of GMP be carried out. Future 
analytical studies on ciprofloxacin in Lagos State should consider assessing dissolution tests in solutions of different $\mathrm{pH}$ to determine in-vitro invivo correlation.

\section{ACKNOWLEDGEMENTS}

Dr. Bukky Oyetunde and Moshood Akinleye for their contributions to the study design; Mr. Peter Ojobor and Mr. David Ikpehae assisted with carrying out the experiments; Dr. Chimezie Anyakora for donating ciprofloxacin pure powder (USP)

\section{REFERENCES}

Abebe, E., Olumide, A., and Oke, M. (2001). A manual for health workers on syndromic management of STIs. National AIDS and STD control program; Federal Ministry of Health, Abuja. PP. 3-7.

Adegbolagun, O.A., Olalade, O.A. and Osumah, S.E. 2007. Comparative evaluation of the biopharmaceutical and chemical equivalence of some commercially available brands of ciprofloxacin hydrochloride tablets. Tropical Journal of Pharmaceutical Research 6 (3):737-745

Adepoju-Bello, A.A., Coker, H.A.B. and Abioye, A.O. 2007. Quinolones: A review. Nigerian Journal of Pharmacy 40:58-63.

Adu-Sarkodie, Y.A. 1997. Antimicrobial selfmedication in patients attending a sexually transmitted diseases clinic. Int $J$ STD AIDS 8:456-458

Allen, L.V., Popovich, N.G. and Ansel, H.C. 2004. "Ansel's pharmaceutical dosage forms and drug delivery systems" in, 8th Edition edn, Lippincott Williams \& Wilkins, Philadelphia.

Anderson, M.I. and MacGowan, A.P. 2003. Development of the quinolones. $J$ Antimicrob Chemother 51 Suppl.1:1-11.

Andriole, V.T. 1988. Clinical overview of the newer 4-quinolone antibacterial agents. In: Andriole VT, ed. The quinolones. London. London Academic Press.

Arya, S.C. 1995. Inadvertent supply of substandard drugs. World Health Forum. 16:269.
Bate, R., Tren, R., Mooney, L., Hess, K., Mitra, B., Debrov, B. and Attaran, A. (2009) Pilot study of essential drug quality in two major cities in India. PLoS One 23;4(6):e6003.

Bennett, S., Quick, J. and Velásquez, G. 1997. Public-Private roles in the pharmaceutical sector: Implications for equitable access and rational drug use. World Health Organization, Geneva, DAP Series No. 5.

Bleidorn J, Gágyor I, Kochen MM, Wegscheider K and Hummers-Pradier E. 2010. Symptomatic treatment (ibuprofen) or antibiotics (ciprofloxacin) for uncomplicated urinary tract infection? Results of a randomized controlled pilot trial_BMC Medicine 8:30

BP, 2007. British Pharmacopoeia, 2007. British Pharmacopoeia Commission, London

Campoli-Richards, D.M., Monk, J.P., Price, A., Benfield, P., Todd, P.A. and Ward, A. 1988. ADIS Drug Information Services, Auckland. Ciprofloxacin: A Review of its antimicrobial activity, pharmacokinetic properties and use. Drugs 373-447.

Chambers, H.F. 2006. General principles of antimicrobial therapy. In: Goodman and Gilman's Pharmacological Basis of Therapeutics. Bruton LL(ed), 11th Ed., McGraw Hill: USA.

Chandrasekaran, A.R, Yi Han, C., Chung, A.C., Cheang, L.W. and Ping, L.S. 2011. Post Market In-Vitro Equivalency of Paracetamol Tablets in Kedah, Malaysia. International Journal of Pharmacentical Sciences and Nanotechnology 4(2):1403-1407

Christian, L., Collins, L., Kiatgrajai, M., Merle, A., Mukherj, N. and Quade, A. 2012. The problem of substandard medicines in developing countries: Report of Workshop on International Public Affairs. La Follette School of Public Affairs, University of Wisconsin-Madison. Available at: http://www.lafollette. wisc.edu/images/publications/workshop s/2012-medicines.pdf. Accessed $19^{\text {th }}$ September 2017

Covington, T. 1992. Generic drug utilization: 
Overview and guidelines for product use. Clin. Res. Reg. Affairs 9:103-126.

Cunningham, S.D., Tschann, J., Gurvey, J.E., Fortenberry, J.D. and Ellen, J.M. 2002. Attitudes about sexual disclosure and perceptions of stigma and shame. Sex Transm Infect. 78:334-338

Dixon-Woods, M., Stokes, T., Young, B., Phelps, K., Windrigde, K. and Shukla, R. 2001. Choosing and using services for sexual health: a qualitative study of women's views. Sex Transm Infect. 77:335-339.

Elsea, S.H., Osheroff, N. and Nitiss, J.L. 1992. Cytotoxicity of quinolones toward eukaryotic cells. Identification of topoisomerase II as the primary cellular target for the quinolone CP-115,953 in yeast.

Emani, J. 2006. In vitro - in vivo Correlation: From Theory to Applications. J Pharm Pharm Sci. 9(2):169-189

FDA, 1997. US Food and Drug Administration. Center for Drug Evaluation and Research (CDER): Guidance for Industry: Dissolution Testing of Immediate Release Solid Oral Dosage Forms.

FDA, 2000. US Food and Drug Administration, Center for Drug Evaluation and Research (2000). Guidance for Industry - Waiver of in vivo bioavailability and bioequivalence studies for immediate-release solid oral dosage forms based on a Biopharmaceutics Classification System, A v a i 1 a b 1 e a t : http://www.fda.gov/cder/guidance/3618 fnl.pdf. Accessed 11th August 2012.

FDA, n.d. US Food and Drug Administration. Guidance for Industry: Extended Release Oral Dosage Forms Development, Evaluation and Application of InVitro/In-Vivo Correlations. Available at: http://www.fda.gov/downloads/Drugs/ GuidanceComplianceRegulatoryInform ation/Guidances/UCM070239.pdf. Accessed 11th August 2012

Frankish, H. 2003. WHO steps up campaign on counterfeit drugs. The Lancet 362(9397):1730
Giri, T.K., Parveen, N., Thakur, D., Alexander, A., Ajazuddin, Badwaik, H. and Tripathi, D.K. 2012. In vitro evaluation of commercially available enteric coated tablet containing diclofenac sodium. International Journal of Research in Pharmacentical and Biomedical Sciences 3(2):875-881

Graciela, I.R. 2001. Argentina to crack down on pharmaceutical black market. The Lancet 358:47.

Haider, S. and Thaver, I. 1995. Self-medication or self-care: implications for primary health care strategies. J Pak Med Assoc. 45:297-298

Hart, C.A. and Kariuki, S. 1998. Antimicrobial resistance in developing countries: Review. BMJ 317:647-650

Hogerzeil, H.V., De Goeje, M.J. and Abu-Reid, I.O. 1991. Stability of essential drugs in Sudan. The Lancet 338: 754.

Ibezim, E.C., Attama, A.A., Obitte, N.C., Onyishi, V.I. and Brown, S.A. 2008. In vitro prediction of in vivo bioavailability and bioequivalence of brands of metronidazole tablets in Eastern Nigerian drug market. Scientific Research and Essay 3(11):552-558

Ilupeju, T.O., Oladeinde, E.O., Olaniyi, A.A. and Amosu, M. 2001. Bioequivalence study of multi-sourced (generic) co-trimoxazole tablets in human urine. In: Olaniyi, A.A., Babalola, C. P., Oladeinde, E.O. and Adegoke, A.O (eds.) Towards Better Quality assurance of Drugs in the 3rd Millennium- Biopharmaceutical methods in drug quality assurance. $1^{\text {st }} \mathrm{ed}$. Ibadan, Nigeria Omoade printing Press.

Johnson, A.M., Wadsworth, J., Wellings, K. and Field, J. 1996. Who goes to sexually transmitted disease clinics? Results from a national population survey. Genitourin Med. 72:197-202.

Kafle, K.K., Gratoulla, R.P., Pradhan, Y.M.S., Shrestha, A.D., Karkee, S.B. and Quick, J.D. 1998. Drug retailer training experiences from Nepal. Soc Sci Med. 35:1015-1025.

Kahsay, G. and G/Egziabher, A. 2010. Quality Assessment of the Commonly Prescribed 
Antimicrobial Drug, ciprofloxacin tablets marketed in Tigray, Ethiopia. Momona Ethiopian Journal of Science (1):93-107

Kasim, N.A., Whitehouse, M., Ramachandran, C., Bermejo, M., Lennernas, H., Hussain, A.S., Junginger, H.E., Stavchansky, S.A., Midha, K.K., Shah, V.P. and Amidon, G.L. 2004. Molecular properties of WHO essential drugs and provisional biopharmaceutical classification. Mol. Pharm.1(1):85-96.

Kelesidis, T., Kelesidis, I., Rafailidi, P.I. and Falagas, M.E. 2007. Counterfeit or substandard antimicrobial drugs: a review of the scientific evidence. I Antimicrob Chemother. 60:214-236

Laurence, D.R., Bennet, P.N. and Brown, M.J. 2003. Clinical Pharmacology, $8^{\text {th }}$ edition. Churchill Livingstone, Philapdelphia. 2003

Maponga, C. and Ondari, C. 2003. The quality of antimalarials: A study in selected African countries. World Health Organisation. Geneva.WHO/EDM/PAR/2003.4.

Merchant, H.A, Shoiab, H.M., Tazeen, J. and Yousuf, R.I. 2006. A once daily tablet formulation and in vitro release evaluation of cepfodoxime using hydroxypropyl methylcellulose: A technical note. AAPS Pharm SciYech. 7(3) article 78

Meredith, P. 2003. Bioequivalence and other unresolved issues in generic drug substitution. Clin. Ther. 25:2875-2890.

Ngwuluka, N.C., Lawal, K., Olorunfemi, P.O. and Ochekpe, N.A. 2009. Post-market in vitro bioequivalence study of six brands of ciprofloxacin tablets/caplets in Jos, Nigeria. Scientific Research and Essay 4(4):298-305.

O'Donnell, J.A. and Gelone, S.P. 2000. Fluoroquinolones. Infect Dis Clin North Am.14(2):489-513

Osadebe, P.O., Esimone, C.O. and Akabogu, I. 2003. An empirical assessment of the possibility of interchangeability between multisource ciprofloxacin hydrochloride tablets marketed in Nigeria. Boll Chim Farm.142:352-356.
Osonwa, U.E., Agboke, A.A., Amadi, R.C., Okorie, O. and Opurum, C.C. 2011. Bioequivalence studies on some selected brands of ciprofloxacin hydrochloride tablets in the Nigerian market with ciproflox ${ }^{\circledR}$ as innovator brand. Journal of Applied Pharmaceutical Science 01(06): 80-84

Shakoor, O., Taylor, R.B. and Berhens, R.H. 1997. Assessment of the incidence of substandard drugs in developing countries. Trop. Med. Int. Health 2:839-845.

Sihavong, A., Lundborg, C.S., Syhakhang, L., Akkhavong, K., Tomson, G. and Wahlström, R. 2006. Antimicrobial selfmedication for reproductive tract infections in two provinces in Lao People's Democratic Republic. Sex Transm Infect. 82:182-186

Siva, N. 2010. Tackling the booming trade in counterfeit drugs. The Lancet. 376 (9754):1725-172

Stenson, B., Lindgren, B.H., Syhakhang, L. and Tomson, G. 1998. The quality of drugs in private pharmacies in the Lao People's Democratic Republic. Int J Risk Saf Med. 11:243-249

Talan DA, Naber KG, Palou J and Elkharrat D. (2004) Extended-release ciprofloxacin (Cipro XR) for treatment of urinary tract infections International Journal of Antimicrobial Agents 23(1):54-66

Taylor, R.B., Shakoor, O., Behrens, R.H., Everard, M., Low, A.S., Wangbooskul, J., Reid, R.G. and Kolawole, J.A. 2001. Pharmacopoeial quality of drugs supplied by Nigerian pharmacies. The Lancet357:1933-36.

ten Ham, M. 1992. Counterfeit drugs: Implications for health. Adverse Drug React and Toxicol Rev. 11:59-65.

USP, 1995. US Pharmacopeia National Formulary USP 23/NF 18. United States Pharmacopeial Convention. Inc., Rockville, MD

USP, 2004. US Pharmacopeia National Formulary USP 27/NF 22. United States Pharmacopeial Convention. Incorporation., Rockville, MD. 
Wentland, M.P. 1993. In memoriam: Lesher GY, In: Hooper DC, Wolfson JS. (eds): Quinolone antimicrobial agents, ed. Washington DC, American Society for Microbiology: XIII - XIV

WHO, 1992. World Health Organization, Counterfeit drugs: report of a joint WHO/IFPMA workshop, World Health Organization, WHO/DMP/CFD/92, Geneva.

WHO, 2003. World Health Organization. Substandard and counterfeit medicines. http://www.who.int/mediacentre/factsh eets/2003/fs275/en. 2003. Accessed 12th August 2012

WHO, 2006. WHO Technical Report Series 937. $40^{\text {th }}$ Report. WHO Expert Committee on Specifications for Pharmaceutical Preparations. Geneva.
WHO, 2007. Global strategy for the prevention and control of sexually transmitted infections: Breaking the chain of transmission 2006 - 2015. World Health Organization. Department of Reproductive Health and Research.

WHO, n.d. World Health Organization. (WHO). What are substandard medicines? http://www.who.int/medicines/services/ counterfeit/faqs/06/en/. Accessed $12^{\text {th }}$ August 2012.

Wu, C. and Benet, L.Z. 2005. Predicting drug disposition via application of BCS: Transport/Absorption/ Elimination interplay and development of a Biopharmaceutics Drug Disposition Classification System. Pharm. Res. 22(1):11-23. 